\title{
Low temperature bonding of heterogeneous materials using Al2O3 as an intermediate layer
}

Sahoo, Hitesh Kumar; Ottaviano, Luisa; Zheng, Yi; Hansen, Ole; Yvind, Kresten

Published in:

Proceedings of SPIE

Link to article, DOI:

$10.1117 / 12.2289526$

Publication date:

2018

Document Version

Publisher's PDF, also known as Version of record

Link back to DTU Orbit

Citation (APA):

Sahoo, H. K., Ottaviano, L., Zheng, Y., Hansen, O., \& Yvind, K. (2018). Low temperature bonding of heterogeneous materials using Al2O3 as an intermediate layer. In Proceedings of SPIE (Vol. 10535). [105350V] SPIE - International Society for Optical Engineering. Proceedings of SPIE - The International Society for Optical Engineering https://doi.org/10.1117/12.2289526

\section{General rights}

Copyright and moral rights for the publications made accessible in the public portal are retained by the authors and/or other copyright owners and it is a condition of accessing publications that users recognise and abide by the legal requirements associated with these rights.

- Users may download and print one copy of any publication from the public portal for the purpose of private study or research.

- You may not further distribute the material or use it for any profit-making activity or commercial gain

- You may freely distribute the URL identifying the publication in the public portal 


\section{Low temperature bonding of heterogeneous materials using $\mathrm{Al}<$ sub $>2</$ sub $>0<$ sub $>3</$ sub $>$ as an intermediate layer}

Hitesh Kumar Sahoo, Luisa Ottaviano, Yi Zheng, Ole Hansen, Kresten Yvind

Hitesh Kumar Sahoo, Luisa Ottaviano, Yi Zheng, Ole Hansen, Kresten Yvind, "Low temperature bonding of heterogeneous materials using Al< sub $>2</$ sub $>0<$ sub $>3</$ sub $>$ as an intermediate layer," Proc. SPIE 10535, Integrated Optics: Devices, Materials, and Technologies XXII, 105350V (23 February 2018); doi: 10.1117/12.2289526

SPIE. Event: SPIE OPTO, 2018, San Francisco, California, United States 


\title{
Low Temperature bonding of heterogeneous materials using $\mathrm{Al}_{2} \mathrm{O}_{3}$ as an intermediate layer
}

\author{
Hitesh Kumar Sahoo ${ }^{\mathrm{a}}$, Luisa Ottaviano ${ }^{\mathrm{a}}$, Yi Zheng ${ }^{\mathrm{a}}$, Ole Hansen ${ }^{\mathrm{b}}$, and Kresten Yvind ${ }^{\mathrm{a}}$ \\ ${ }^{a}$ DTU Fotonik, Building 343, Ørsteds Plads, DK-2800 Kongens Lyngby, Denmark \\ ${ }^{\mathrm{b}}$ DTU Nanotech, Building 345C, Ørsteds Plads, DK-2800 Kongens Lyngby, Denmark
}

\begin{abstract}
Direct wafer bonding is a key enabling technology for many current and emerging photonic devices. Most prior work on direct wafer bonding has, however, focused on the Si platform for fabrication of silicon-on-insulator (SOI) and micro-electromechanical systems (MEMS). As a result, a universal bonding solution for heterogeneous material systems has not yet been developed. This has been a roadblock in the realization of novel devices which need the integration of new semiconductor platforms such as III-V on $\mathrm{Si}$, Ge on Sapphire, $\mathrm{LiNbO}_{3}$ on GaAs etc. The large thermal expansion coefficient mismatch in the hetero-material systems limits the annealing to low temperatures to avoid stressed films. This work explores the use of $\mathrm{Al}_{2} \mathrm{O}_{3}$ as an intermediate layer for bonding heterogeneous materials. The key to achieve a stronger bond is to maximize the hydroxyl group density of the bonding interfaces. The use of $\mathrm{Al}_{2} \mathrm{O}_{3}$ helps achieve that, since it has a high hydroxyl group density (around 18 $\mathrm{OH} / \mathrm{nm}^{2}$ at $\mathrm{RT}$ ) which is approximately 4 times that of a $\mathrm{Si}$ surface. This work optimizes the bonding process using $\mathrm{Al}_{2} \mathrm{O}_{3}$ by studying the contribution of $\mathrm{Al}_{2} \mathrm{O}_{3}$ deposition parameters. An optimized process is presented and applied to bond GaAs on Sapphire and $\mathrm{InP}$ on $\mathrm{SiO}_{2} / \mathrm{Si}$.
\end{abstract}

Keywords: direct bonding, Al2O3, low temperature, Si photonics, integration, heterogeneous

\section{INTRODUCTION}

Often bonding of two different materials is needed to realize advanced devices, and then direct wafer bonding is a better and cleaner choice compared to polymer adhesive bonding, eutectic bonding, or anodic bonding etc. The requirements for a good direct bond are an ultra-clean and smooth hydrophilic surface. When bondable surfaces are brought in contact at room temperature, the two surfaces are initially bonded by hydrogen bonding. A high-temperature annealing process follows to achieve covalent bonds at the interface. The seminal work of Maszara et al. ${ }^{1}$ and Tong and Gösele ${ }^{2}$ still provide the fundamental understanding of direct wafer bonding. Maszara et al. highlighted the importance of high-temperature annealing for achieving high interface energy. Tong and Gösele, on the other hand, studied optimization of the annealing parameters to maximize the interface energy. This process technology, however, cannot be applied directly to heterogeneous material systems. First and most importantly, the difference in thermal expansion coefficient may limit the annealing temperature to avoid thermal stress in the bonded sample. InP wafers bonded to $\mathrm{Si}$ wafers, for example, start showing defects when annealed above $300{ }^{\circ} \mathrm{C} .{ }^{3}$ Secondly, bonding is a surface phenomenon with a strong dependence on the surface chemistry of the bonding surfaces. Thus, the process technology developed for one set of wafers may or may not be adapted to a new pair of materials. Finally, most of the bonding process flows involve a surface activation step which may increase the surface roughness of the wafers. Often, it is recommended to break the surface bonds by an $\mathrm{O}_{2}$ plasma or Ar sputtering followed by a dip in de-ionized water (DIW). A dip in water prior to bonding is often undesirable, especially when one of the wafers has micro-electro-mechanical structures (MEMS) defined. ${ }^{4}$ This work aims to address all the above-mentioned concerns and suggests a low-temperature bonding process for hetero-material systems.

An ideal bonding method should be able to achieve a strong bond even with a low annealing temperature. The density of hydroxyl groups on the surface of the bonding wafers holds the key to a good bond. The higher

Further author information: (Send correspondence to H.K.S.)

H.K.S.: E-mail: hikus@fotonik.dtu.dk

Integrated Optics: Devices, Materials, and Technologies XXII, edited by Sonia M. García-Blanco,

Pavel Cheben, Proc. of SPIE Vol. 10535, 105350V · C 2018 SPIE

"CCC code: 0277-786X/18/\$18 - doi: 10.1117/12.2289526

Proc. of SPIE Vol. 10535 105350V-1 
the number of hydroxyl groups, the higher is the number of linkages between the two wafers. A silicon surface has a hydroxy surface density of approximately $4 \mathrm{OH} / \mathrm{nm}^{25,6}$ while an $\mathrm{Al}_{2} \mathrm{O}_{3}$ surface has a hydroxyl group density around $18 \mathrm{OH} / \mathrm{nm}^{2}{ }^{7,8}$ Thus, two wafers with $\mathrm{Al}_{2} \mathrm{O}_{3}$ as the bonding interface will be almost four times stronger than that of bare silicon. Furthermore, $\mathrm{Al}_{2} \mathrm{O}_{3}$ can be deposited with high precision using atomic layer deposition (ALD) at rather low temperature; thus it can be used as an intermediate layer also for bonding hetero-material systems. A high density of hydroxyl groups ensures a strong bond even at a low temperature. With limited studies in this direction, ${ }^{9-12}$ this work builds on the established knowledge and aims to establish a process flow which can be applied to most material systems.

\section{EXPERIMENT}

The Maszara blade test ${ }^{1}$ is one of the most commonly used bond strength characterization methods. The Maszara test is relatively simple to carry out but is destructive. For III-V materials, however, the Maszara test is almost impossible to carry out, since the materials are too brittle for the test. Moreover, III-V materials are quite expensive to sacrifice for such characterization steps. Thus, in most cases, substrate etching is used as a qualitative method to characterize the bond quality of III-V materials. To address this concern, silicon wafers were used for understanding $\mathrm{Al}_{2} \mathrm{O}_{3}$ based bonding and optimizing the process technology. Later, the optimized process flow was applied to hetero-material systems and substrate etch was done to look at the bond quality qualitatively.

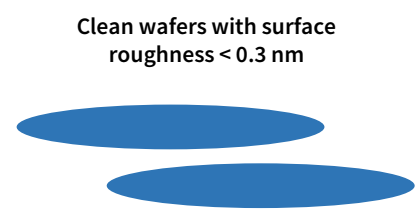

(a)

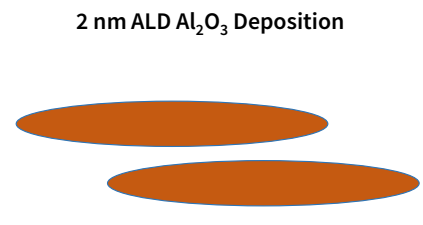

(b)

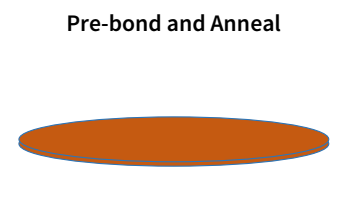

(c)

Figure 1. Illustration of the steps used for bonding wafers with $\mathrm{Al}_{2} \mathrm{O}_{3}$ as an intermediate layer. (a) The wafers need to be clean with a surface roughness $<0.3 \mathrm{~nm}$. (b) The wafers are coated with a few mono layers of $\mathrm{ALD} \mathrm{Al}_{2} \mathrm{O}_{3}$. (c) Finally, the wafers are placed on top of each other (pre-bonded) and annealed at the maximum permissible temperature. A controlled pressure is also applied during the annealing step to reduce the size of voids due to particles.

Figure 1 illustrates the basic process flow used in this experiment. Prime grade single crystal (100) 2-inch silicon wafers from a new wafer box were used for the experiments and no additional cleaning steps were done. Two silicon wafers were loaded into a commercial ALD chamber to deposit a few monolayers of $\mathrm{Al}_{2} \mathrm{O}_{3}$ and the wafers were pre-bonded right out of the chamber. By pre-bonding, we refer to the placement of bondable wafers together and the wafers being held by hydrogen bonds. The pre-bonded wafers were then placed in a commercial wafer bonding system for annealing at $300{ }^{\circ} \mathrm{C}$ for $60 \mathrm{~min}$. A force of $2 \mathrm{kN}$ was applied on 2-inch pre-bonded wafers during the annealing process to minimize voids from particles.

The interface energy of the bonded wafers was determined using the setup shown in Figure 2. The sample (bonded wafers with an inserted metal strip) was placed on a double side polished (DSP) 6-inch Si wafer. The sample was illuminated from below the Si wafer using an IR lamp and the image was collected using a camera from the top. A change in contrast between the bonded and de-bonded region was used to obtain the required parameters to calculate the interface energy. (Figure 3) A $50 \mu \mathrm{m}$ steel strip was inserted between the bonded silicon wafers to cause delamination. The interface energy was calculated using ${ }^{1}$

$$
\gamma=\frac{3}{32} \frac{E t^{3} y^{2}}{L^{4}}
$$

where $E$ is Young's modulus of the material ( $\mathrm{Si}$ ), $t$ is the thickness of the wafers, $y$ is the thickness of the blade and $L$ is the crack length. An experimental error of $\pm 15 \%$ is typically assumed for the Maszara test. At least four different measurements for each point were performed to obtain the standard deviation, shown in the results discussed next. 


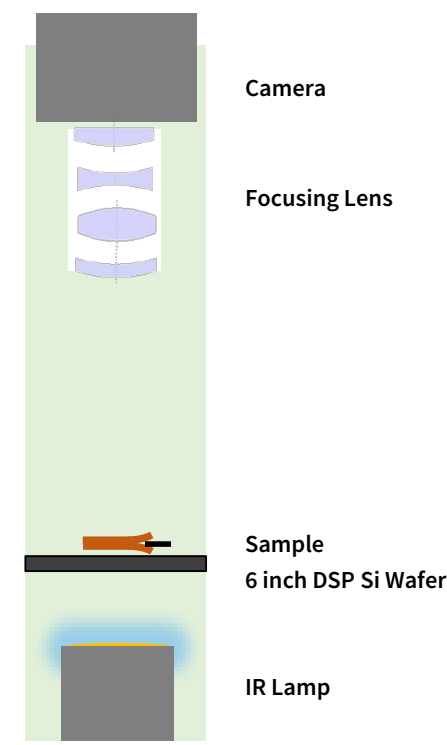

Figure 2. Schematic illustration of the setup used for the Maszara test. A bonded sample with an inserted metal strip is placed on a double side polished (DSP) 6" Si wafer. An IR lamp below the Si wafer is used to illuminate the sample. An IR camera with an adjustable lens is fixed on top of the setup for capturing an image of the sample.

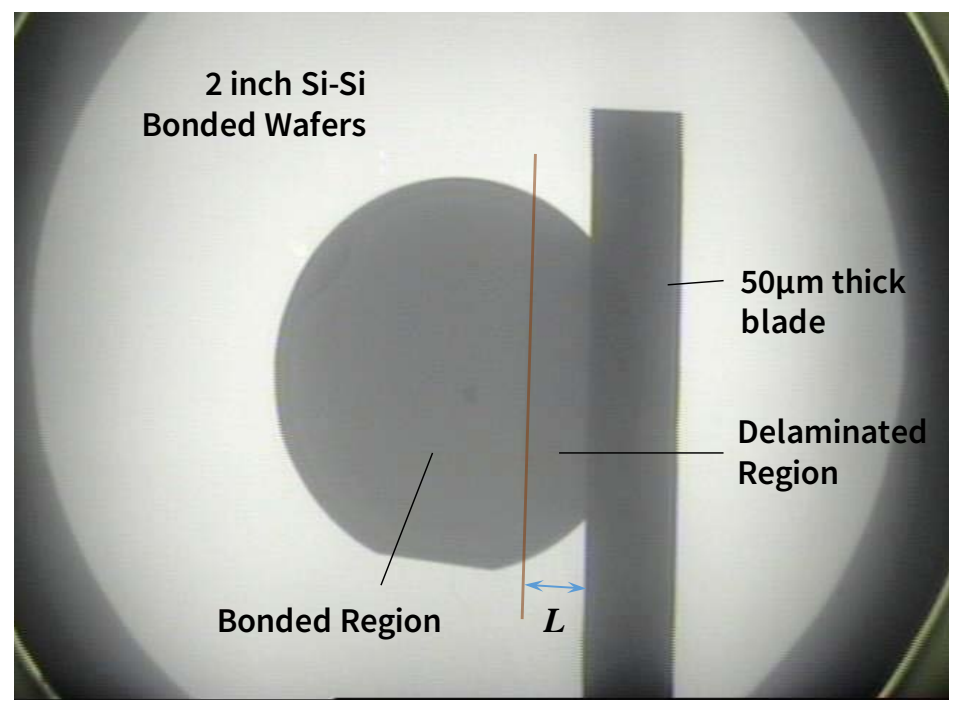

Figure 3. IR camera image with overlayed information obtained from the Maszara test using the setup shown in Figure 2.

\section{DISCUSSION}

Bonding is a surface phenomenon which implies that the material properties of the surface should be important. The bonding process discussed here uses $\mathrm{Al}_{2} \mathrm{O}_{3}$ as the intermediate layer. Thus, the deposition parameters of $\mathrm{Al}_{2} \mathrm{O}_{3}$ influence the achieved interface energy. In particular, the effects of the thickness of $\mathrm{ALD}^{\mathrm{A}} \mathrm{O}_{2} \mathrm{O}_{3}$ and the ALD temperature on the interface energy are explored in this paper.

To study the effect of $\mathrm{ALD} \mathrm{Al}_{2} \mathrm{O}_{3}$ on the bond quality, different thicknesses of $\mathrm{Al}_{2} \mathrm{O}_{3}$ were deposited at 200 ${ }^{\circ} \mathrm{C}$ on $\mathrm{Si}$ wafers, which were then bonded and annealed at $300{ }^{\circ} \mathrm{C}$ for $60 \mathrm{~min}$. Figure 4 shows the bond strength of

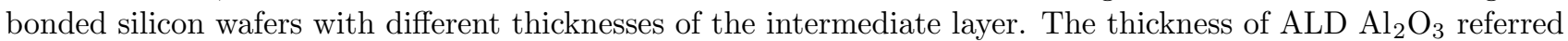




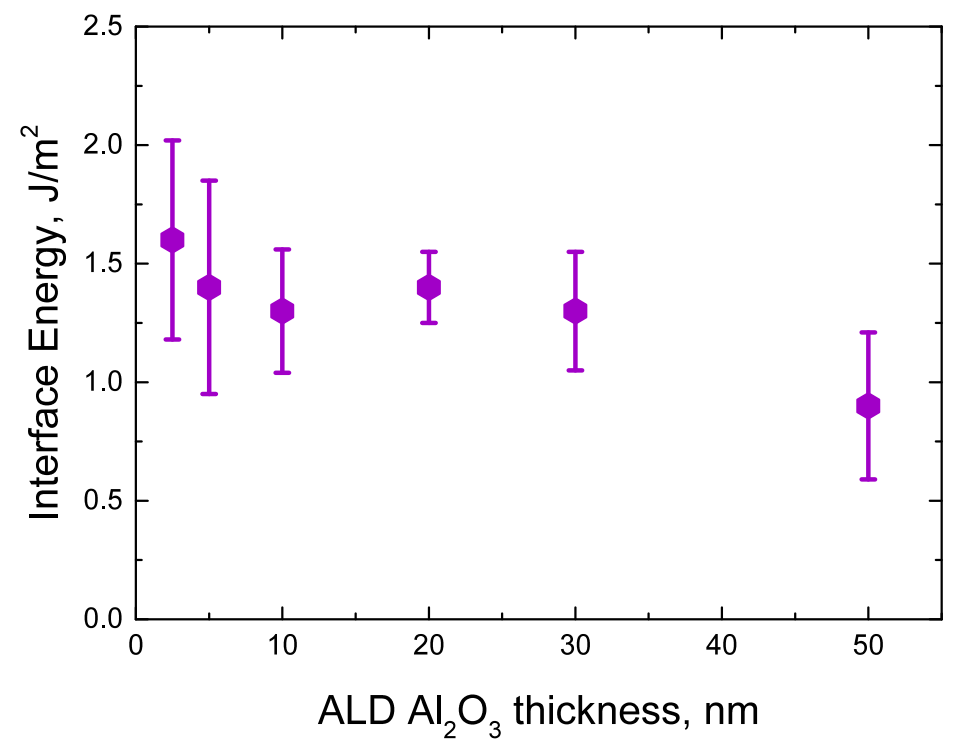

Figure 4. Interface energy of bonded $\mathrm{Si}$ wafers using $\mathrm{Al}_{2} \mathrm{O}_{3}$ based bonding (measured using the Maszara test) plotted against the thickness of intermediate $\mathrm{Al}_{2} \mathrm{O}_{3}$ used. The bonded samples were annealed at $300{ }^{\circ} \mathrm{C}$ for 60 min using a commercial wafer bonding setup.

to here is the thickness deposited on each wafer. As expected, the thickness of the deposited $\mathrm{Al}_{2} \mathrm{O}_{3}$ did not have a significant influence on the interface energy of the bonded samples. As little as $2 \mathrm{~nm}$ of $\mathrm{Al}_{2} \mathrm{O}_{3}$ was enough to form a strong bond. The minimum deposited thickness of $\mathrm{Al}_{2} \mathrm{O}_{3}$ discussed in this paper is $2 \mathrm{~nm}$ to ensure a uniform film deposition of $\mathrm{Al}_{2} \mathrm{O}_{3}$ on the entire wafer. The interface energy corresponding to $50 \mathrm{~nm}$ of $\mathrm{Al}_{2} \mathrm{O}_{3}$ was slightly lower than that of the remaining samples. The achieved bond strength was quite high and there were no voids observable in the IR camera. Many reports suggest the need for a thick oxide film to achieve a void-free bonding. ${ }^{13-15}$ When a pre-bonded wafer is annealed, water molecules from the bond interface diffuse to the $\mathrm{Si}$ surface where they react with silicon to form silicon dioxide and hydrogen, the resulting hydrogen escapes to the interface to form voids. The hydrogen may also be dissolved in the thick oxide. However, $\mathrm{Al}_{2} \mathrm{O}_{3}$ is denser than $\mathrm{SiO}_{2}$ and thus has a low diffusivity for water molecules. ${ }^{16}$ Low water diffusivity has also been shown by Ventonsa et al. ${ }^{17}$ using pre-annealed $\mathrm{SiO}_{2}$. Thus, the water molecules most likely get trapped at the bond interface and fill up any nanovoids arising from surface roughness of the bonding wafers. The water molecules being denser than hydrogen occupy less volume and thus the voids are invisible.

The hydroxyl group density is important to maximize the interface energy. The hydroxyl group density is dependent on the material properties and temperature. Thus, the deposition temperature of $\mathrm{ALD} \mathrm{Al}_{2} \mathrm{O}_{3}$ may also influence the interface energy. Figure 5 shows the bond energy measured for Si wafers bonded with $2 \mathrm{~nm}$ of ALD $\mathrm{Al}_{2} \mathrm{O}_{3}$ deposited at different temperatures. The wafers were then annealed at $300{ }^{\circ} \mathrm{C}$ for 60 min. No clear trend was observed; this may be partly due to the limited temperature region used for this study. Some wafers were also exposed to water vapour (humid environment) prior to pre-bonding. This ensured a saturated hydroxyl group density and this can be verified from the Figure 5. The interface energy of the bonded silicon wafers with a short water vapour exposure was independent of the ALD temperature. Ideally, the ALD coated wafers should be placed on a heat sink for a short time before bonding to ensure re-hydroxylation.

\section{OPTIMIZED BONDING PROCESS}

The wafers still need to be clean and have low surface roughness as is also necessary in direct bonding. However, there is no need for any surface preparation or activation. Deposition of $\mathrm{ALD} \mathrm{Al}_{2} \mathrm{O}_{3}$ ensures a hydroxyl-rich surface without the need for any wet chemistry. More importantly, as little as $2 \mathrm{~nm}$ of $\mathrm{Al}_{2} \mathrm{O}_{3}$ is enough to 


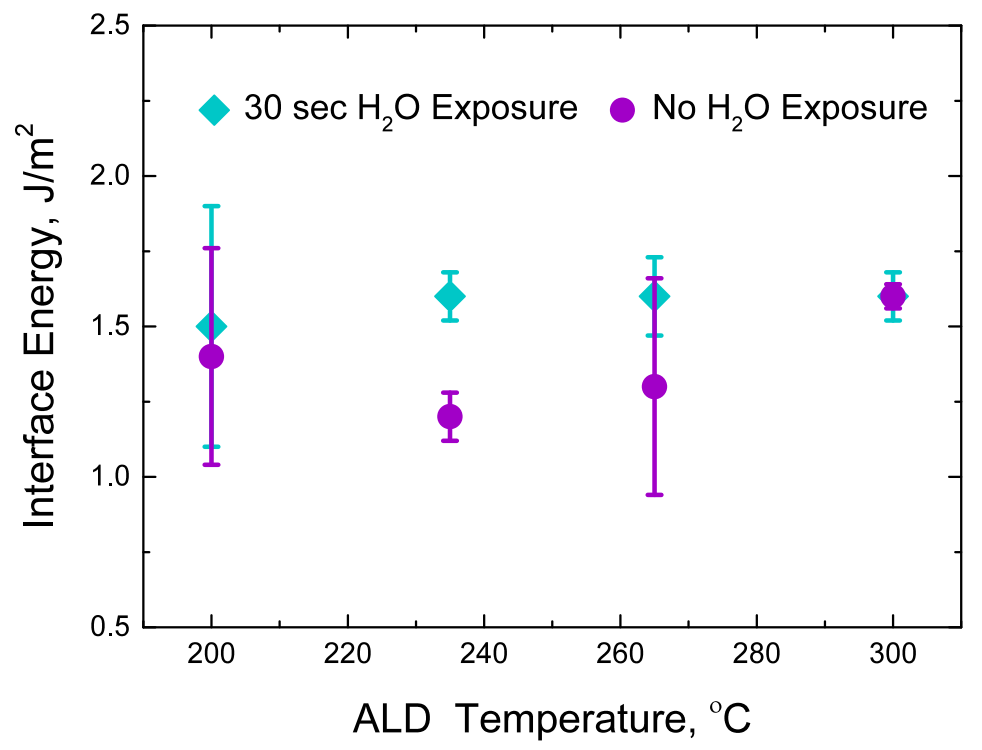

Figure 5. Interface energy of bonded $\mathrm{Si}$ wafers using $\mathrm{Al}_{2} \mathrm{O}_{3}$ based bonding (measured using the Maszara test) plotted for different ALD temperatures. The wafers were coated with approximately $2 \mathrm{~nm}$ of $\mathrm{Al}_{2} \mathrm{O}_{3}$. They were then pre-bonded with/without $30 \mathrm{sec}$ of exposure to water vapor. The pre-bonded wafers were annealed at $300{ }^{\circ} \mathrm{C}$ for $60 \mathrm{~min}$ using a commercial wafer bonding setup before the Maszara test.

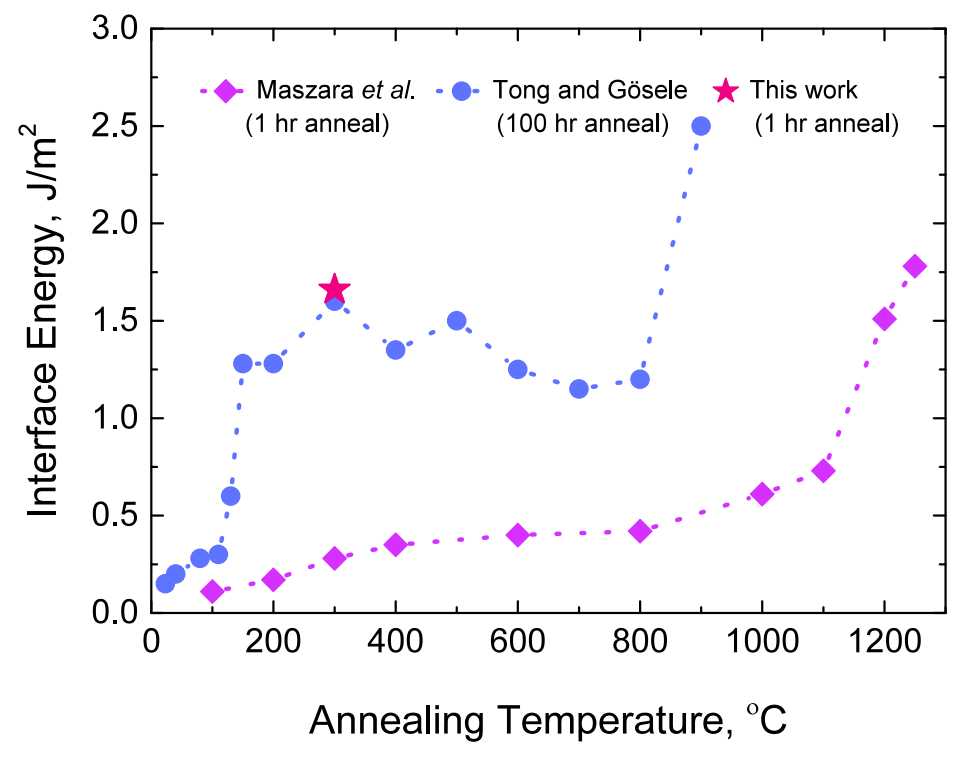

Figure 6. Interface energy of Si-Si wafer bonding as a function of the anneal temperature. Literature data due to Maszara et al. ${ }^{1}$ and Tong and Gösele ${ }^{2}$ are compared to our data from the optimized process using $\mathrm{Al}_{2} \mathrm{O}_{3}$.

achieve a strong bond. The deposition temperature of $\mathrm{Al}_{2} \mathrm{O}_{3}$ is not very important, as long as the wafers are allowed to be re-hydrolyzed. The wafers should then be bonded and annealed at the maximum permissible temperature (considering the relative thermal expansion coefficients) for $60 \mathrm{~min}$. The optimized process flow was used to achieve a high bond strength of $1.7 \mathrm{~J} / \mathrm{m}^{2}$, which is comparable to the bond strength achieved by Tong and Gösele after an annealing time of 100 hours at $300{ }^{\circ} \mathrm{C}$. Likewise, the bond strength is almost equal to that 


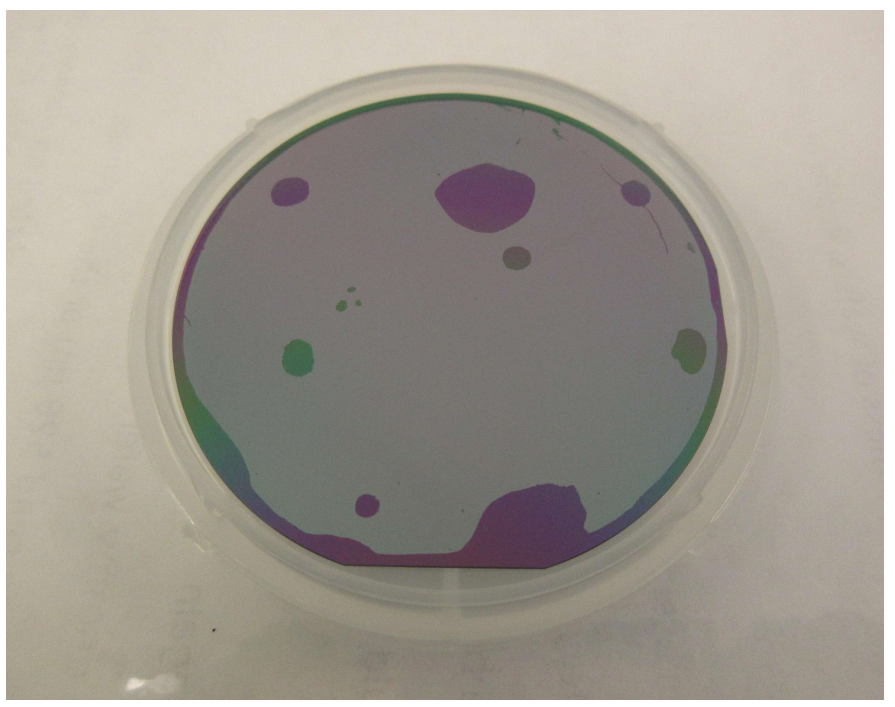

(a)

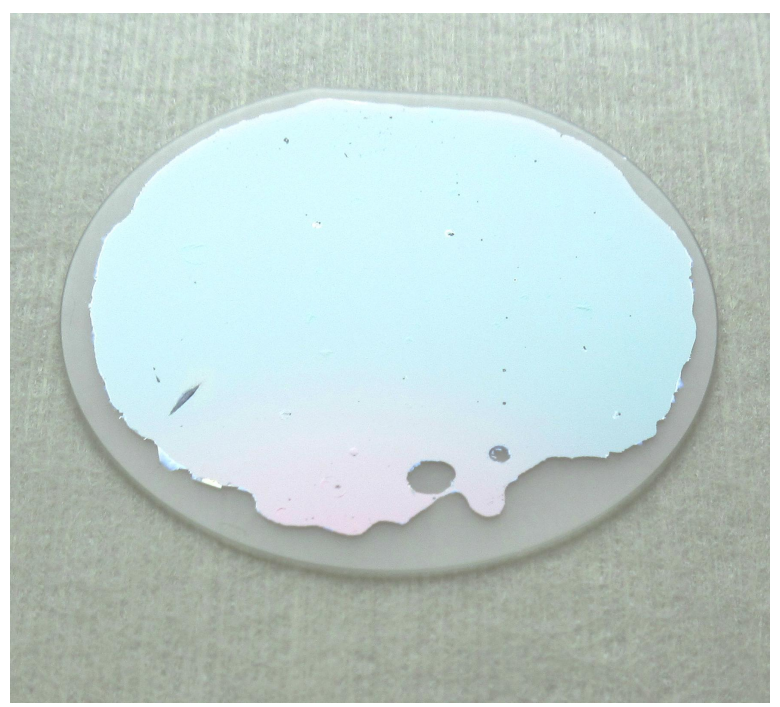

(b)

Figure 7. The optimized bonding process was adapted to wafer bonding of (a) $\mathrm{InP}$ to $\mathrm{SiO}_{2}$ and (b) GaAs to sapphire. The images show the bonded wafers after a complete III-V substrate removal. The un-bonded regions arise from particles introduced before and during the pre-bonding step.

achieved by Maszara et al. after annealing direct bonded Si wafers at around $1200{ }^{\circ} \mathrm{C}$.

The optimized process was adapted to two hetero-material systems: $\mathrm{InP}$ bonded to $\mathrm{SiO}_{2} / \mathrm{Si}$ and $\mathrm{GaAs}$ bonded to sapphire. Figure 7 shows the bonded samples after removal of the III-V substrate. The small un-bonded regions that are visible on the wafers are due to particles from handling of the wafers.

\section{CONCLUSION}

We have studied and optimized a low-temperature bonding process, that use $\mathrm{Al}_{2} \mathrm{O}_{3}$ as an intermediate layer for bonding of hetero-material systems. The process avoids any activation and surface treatment steps thus minimizing handling before bonding. A high bond strength of $1.7 \mathrm{~J} / \mathrm{m}^{2}$ was achieved for silicon wafers bonded using the $\mathrm{Al}_{2} \mathrm{O}_{3}$ intermediate layer. The optimized process was also adapted to bond III-V based hetero-material systems. The new bonding process is expected to enable novel nano-photonic devices in the future.

\section{ACKNOWLEDGMENTS}

The authors acknowledge the financial support from the Danish Innovation Foundation through the HERON project, the Villum Center of Excellence NATEC, and the National Basic Research Foundation centre SPOC (DNRF123). Aurimas Sakanas is acknowledged for providing the image of $\mathrm{InP}$ bonded to $\mathrm{Si} / \mathrm{SiO}_{2}$ in Figure 7 .

\section{REFERENCES}

[1] Maszara, W. P., Goetz, G., Caviglia, A., and McKitterick, J. B., "Bonding of silicon wafers for silicon-oninsulator," Journal of Applied Physics 64(10), 4943-4950 (1988).

[2] Tong, Q.-Y. and Gösele, U., "A model of low-temperature wafer bonding and its applications," Journal of the Electrochemical Society 143(5), 1773-1779 (1996).

[3] Pasquariello, D. and Hjort, K., "Plasma-assisted inp-to-si low temperature wafer bonding," IEEE Journal of Selected Topics in Quantum Electronics 8(1), 118-131 (2002).

[4] Sahoo, H. K., Ansbæk, T., Ottaviano, L., Semenova, E. S., Hansen, O., and Yvind, K., "Optically pumped $1550 \mathrm{~nm}$ wavelength tunable mems vcsel," in [Society of Photo-Optical Instrumentation Engineers (SPIE) Conference Series], 9760 (2016). 
[5] Armistead, C. G., Tyler, A. J., Hambleton, F. H., Mitchell, S. A., and Hockey, J. A., "The surface hydroxylation of silica," Journal of Physical Chemistry 73(11), 3947-3953 (1969).

[6] Zhuravlev, L. T., "The surface chemistry of amorphous silica. zhuravlev model," Colloids and Surfaces A: Physicochemical and Engineering Aspects 173(1-3), 1-38 (2000).

[7] Tsyganenko, A. A. and Mardilovich, P. P., "Structure of alumina surfaces," Journal of the Chemical Society, Faraday Transactions 92(23), 4843 (1996).

[8] Digne, M., Sautet, P., Raybaud, P., Euzen, P., and Toulhoat, H., "Hydroxyl groups on gamma-alumina surfaces: A dft study," Journal of Catalysis 211(1), 1-5 (2002).

[9] Fan, J., Anantha, P., Liu, C. Y., Bergkvist, M., Wang, H., and Tan, C. S., "Thermal characteristics of inp-al2o3/si low temperature heterogeneous direct bonding for photonic device integration," ECS Journal of Solid State Science and Technology 2, N169-N174 (jun 2013).

[10] Fan, J., Tu, L. C., and Tan, C. S., "High-kappa $a l_{2} O_{3}$ material in low temperature wafer-level bonding for 3d integration application," AIP Advances 4, 031311 (mar 2014).

[11] Ikku, Y., Yokoyama, M., Iida, R., Sugiyama, M., Nakano, Y., Takenaka, M., and Takagi, S., "Ald al 2 o 3 activated direct wafer bonding for iii-v cmos photonics platform," in [Compound Semiconductor Week (CSW/IPRM), 2011 and 23rd International Conference on Indium Phosphide and Related Materials], 1-4, IEEE (2011).

[12] Li, Y., Wang, S., Sun, B., Chang, H., Zhao, W., Zhang, X., and Liu, H., "Room temperature wafer bonding by surface activated ald-al2o3," ECS Transactions 50(7), 303-311 (2013).

[13] Plach, T., Hingerl, K., Tollabimazraehno, S., Hesser, G., Dragoi, V., and Wimplinger, M., "Mechanisms for room temperature direct wafer bonding," Journal of Applied Physics 113(9), 094905 (2013).

[14] Ventosa, C., Rieutord, F., Libralesso, L., Morales, C., Fournel, F., and Moriceau, H., "Hydrophilic lowtemperature direct wafer bonding," Journal of Applied Physics 104(12), 123524 (2008).

[15] Vincent, S., Radu, I., Landru, D., Letertre, F., and Rieutord, F., "A model of interface defect formation in silicon wafer bonding," Applied Physics Letters 94(10), 101914 (2009).

[16] Langereis, E., Creatore, M., Heil, S. B. S., Van De Sanden, M. C. M., and Kessels, W. M. M., "Plasmaassisted atomic layer deposition of al2o3 moisture permeation barriers on polymers," Applied Physics Letters 89(8), 2-4 (2006).

[17] Ventosa, C., Rieutord, F., Libralesso, L., Fournel, F., Morales, C., and Moriceau, H., "Prebonding thermal treatment in direct si-si hydrophilic wafer bonding," Journal of The Electrochemical Society 156(11), H818H823 (2009). 